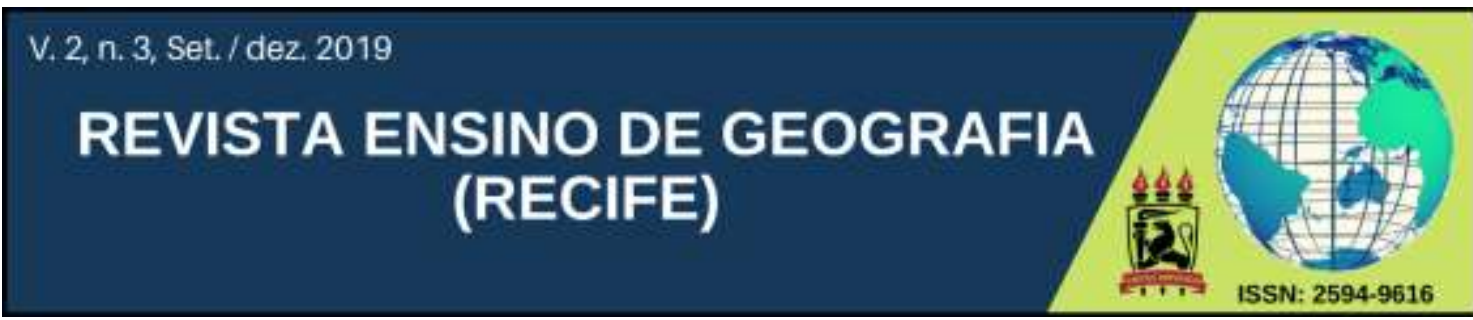

\title{
ALICERCES ÀS AULAS: PRINCÍPIOS, CONCEITOS E CATEGORIAS GEOGRÁFICAS
}

\author{
Adriana Maria Andreis \\ Professora na Universidade Federal da Fronteira Sul - UFFS/Chapecó/SC \\ adriana.andreis@uffs.edu.br \\ ORCID Id: http://orcid.org/0000-0002-5369-3766
}

\author{
Helena Copetti Callai \\ Professor titular da Universidade Regional do Noroeste do Estado do Rio Grande do Sul \\ copetti.callai@gmail.com \\ ORCID Id: https://orcid.org/0000-0001-8043-659X
}

Artigo recebido em 09/01/2020 e aceito em 22/01/2020

\begin{abstract}
RESUMO: A noção e a dimensão espacial, nas pesquisas e no ensino, são objetos de análise em diferentes áreas do conhecimento. Neste artigo, colocamos em discussão as relações entre princípios, conceitos e categorias, para afirmar o espaço como corpus que sustenta a análise espacial pelo viés geográfico. Construímos argumentos que propõem esses processos como enlaces com as temáticas propostas nas aulas e, também, como possibilidade prospectiva e criativa. Metodologicamente, o texto, organizado em três partes que focam essas noções, é configurado como estudo bibliográfico resultante de pesquisas teóricas que dialogam com nossas vivências de professoras. A investigação permite inferir, conjugando o natural e o social, que os princípios são leis elaboradas, os conceitos são generalizações e as categorias são modos de abordar. São possibilidades de realização da análise espacial, assumida pela arguição envolvendo a singularidade e a associação entre essas noções, e essas sistematizações são possibilidades à imaginação criadora.
\end{abstract}

Palavras-chave: Ensino de Geografia. Princípios geográficos. Aportes teóricos. Aprendizagem. Construção de conhecimentos.

\section{FOUNDATIONS FOR CLASSROOMS: GEOGRAPHICAL PRINCIPLES, CONCEPTS AND CATEGORIES}

The notion and spatial dimension in research and teaching are objects of analysis in different areas of knowledge. In this article, we put in discussion the relationship between principles, concepts and categories, to say the space as corpus that supports spatial analysis by geographic bias. We construct arguments that propose these processes as links to the themes proposed in class and also as forward-looking and creative possibility. Methodologically, text, organized into three sections that focus on these notions, is configured as a result bibliographical study of theoretical research that dialogue with our experiences of teachers. The research allows us to infer, combining natural and social that the principles are designed laws the concepts are generalizations and categories are ways of approaching. They are possibilities for realization of spatial analysis, taken by the complaint involving the uniqueness and the association between these notions, and these systematizations should are possibilities to the creative imagination.

Key words: Geography Teaching. Geographical principles. Theoretical contributions. Learning. Construction of knowledge. 


\section{INTRODUÇÃO: A AULA DE GEOGRAFIA}

Refletir sobre a aula de geografia é considerar e pensar a vida da escola reconhecendo todos os aspectos que nela acontecem. Nesse complexo, a noção de alicerce é uma afirmação densa, porque princípios, conceitos e categorias geográficas, por sua implicação espaçotemporal, são importantes por compreenderem a natureza das aprendizagens escolares em geral. Tendo isso como pressuposto, entendemos ser significativa a reflexão acerca da sustentação teórica da aula de Geografia, pois seus enlaces teóricos envolvem dispositivos à construção de conhecimentos.

A aula, não só a de Geografia, mas de outras disciplinas inclusive, é um ato-evento que compreende um espaço-tempo de interação entre sujeitos em processo de dar um passo (BAKHTIN, 2010). Traz, em si mesma, diferentes processos sempre abertos. Contudo, apesar de não se configurar e ser entendida como "encontro ritual, e por isso com gestos e fazeres predeterminados, de transmissão de conhecimentos" (GERALDI, 2010, p. 81), também, não é algo aleatório, neutro, distante da vida cotidiana das pessoas.

A preparação do material utilizado e as estratégias desenvolvidas podem ser adequadas e até produzir bons resultados, em termos de elos reflexivos. Mas há algo mais forte por detrás de tudo isso, que é o fundante de todo o processo, que é o "pensamento geográfico". Este acolhe tudo o mais e permite fazer a interlocução com todos os demais aspectos. É o que ajuda a dar sentido à disciplina escolar, e oportuniza o caminho da abstração. Só neste processo pode ser possível construir os conceitos, e são estes que fundam o entendimento dos conteúdos.

Não deixamos de lado o fazer que constitua o cotidiano da sala de aula que é importante que seja conhecido e compreendido. Isso em dois âmbitos. O primeiro é aquele que desafia o professor que está em sala de aula a que faça os exercícios de abstração para teorizar, não apenas os conteúdos com que trabalha, mas a própria ação docente. $\mathrm{O}$ outro âmbito, que é o que nos inserimos neste momento da nossa vida acadêmica, é o de criar as condições operacionais para a pesquisa, não uma pesquisa fechada em si, mas aberta ao mundo da vida. Trata-se de "entender agora o escrever como princípio de vida, impulso vital irresistível, este meu problema, meu: existencial. Mas também, pragmaticamente, meu problema profissional: de professor [...].” (MARQUES, 2008, p. 18).

Nesse conjunto é que apresentamos uma reflexão centrada nas questões que consideramos significativas para desenvolver o pensamento geográfico. Este requer que seja claramente estabelecido o que é central na Geografia e, neste caso de interesse, na disciplina 
escolar. O que é o cerne da Geografia? O que sustenta que ela seja uma ciência com campo próprio e em decorrência uma disciplina com status de singularidades para ser incluída no contexto dos currículos escolares? Só tendo isso claro é que se pode pensar em que conteúdos são abordados e porque são estes os estabelecidos.

A argumentação acerca da importância e das relações entre princípios, conceitos e categorias analíticas, interessada em reconhecer a implicação desse processo no ensinoaprendizagem de Geografia, constitui-se como foco central desta elaboração. A base deste estudo é o que configuramos no âmbito da pesquisa que realizamos entre 2010 e 2014 - no âmbito do doutorado em Educação nas Ciências: concentração Geografia - argumentando o cotidiano como categoria geográfica para ensinar e aprender na escola. Agora, tomamos essa discussão como chave de abertura dos porões - um convite aos professores (especialmente, de Geografia) e aos acadêmicos das licenciaturas - para investigarmos sobre as questões envolvendo a singularidade da análise espacial na educação, compreendidas enquanto elos às possibilidades prospectivas, na construção de conhecimentos.

Colocamos acento na aula, pois é habitat central de todo o processo educativo. E, é fundamental entender que ela compreende a mediação entre o que está além e aquém do “assunto ou conteúdo" em questão. Nela, uma mesma temática pode ser trabalhada por diferentes áreas do conhecimento explorando diversos vieses, pois é o mesmo mundo que é posto em debate, e que pode ser pensado por meio da experimentação de novas vinculações. As relações pedagógicas criadas envolvem ir além do tema da aula, ou seja, implicam dimensão do diálogo prospectivo. Também, compreendem o aquém, no sentido de que envolvem compromisso com as afirmações teóricas resultantes dos acordos provisórios da comunidade científica. Uma espécie de habitar não apenas a casa, de não se limitar ao conteúdo da aula, mas também abrir o sótão e o porão. O primeiro infere apostar na imaginação; o segundo envolve lastrear-se nos alicerces das elaborações conceituais. Do sótão, partimos para os voos criativos; no porão, firmamos nossos pés. Imaginação e inovação têm relação com reflexão e razão (BACHELARD, 1975; VEIGA-NETO, 2012).

Esta discussão, nascida das vivências de professoras de Geografia e das pesquisas que desenvolvemos, compreende pensar sobre o que envolve o porão, que, algumas vezes, é rechaçado por ser considerado como extremamente teórico e distante, ou como passado, morto. Contudo, é nele que se encontram referentes elaborados e que servem aos enlaces, sustentadores da morada, entendida como o assunto ou conteúdo e os procedimentos da aula. São esses aportes que permitem avançar para relações outras, diferentes. O porão lastreia a morada, com 
os conceitos e categorias necessários à sustentação do ensinar e aprender, como elos ao avanço nos entendimentos dos sujeitos.

Esta argumentação, realizamos na modalidade de ensaio teórico, interessado em servir como dispositivo reflexivo; um debate para auxiliar na configuração de relações da Geografia e de outras disciplinas nos processos de ensino-aprendizagem, pautando-se em princípios, conceitos e categorias. Para isso, na primeira parte analisamos a sustentação da aula, dando destaque aos princípios, conceitos e categorias geográficas. Avançamos, apresentando o entrecruzamento dessas dimensões como elaboração dialético-dialógica, apresentada na forma de espiral cíclica, e confluímos afirmando habitar no aquém e além da aula, a sua potência revolucionária.

\section{A SUSTENTAÇÃO TEÓRICA DA AULA}

Ensinar e aprender envolve uma relação complexa, que vem tomando parte dos debates (CALLAI, 2011, 2013), preocupados em refletir sobre os processos e pressupostos epistemológicos envolvidos. A dimensão espacial (que envolve o temporal) compreende a singularidade da aula de Geografia, mas, numa perspectiva de educação integral, é importante para todas as áreas do conhecimento. Também, é importante entender que as representações são construídas em diálogo com as proposições escolares. Por exemplo, as ideias de mundo que são construídas pelos sujeitos, têm relação com os mapas apresentados nas aulas (ANDREIS, 2010). Ratifica-se, assim, a importância de compreender os pressupostos teóricos que envolvem as aulas.

Pôr na mesa a discussão do que sustenta o viés espacial na análise geográfica na escola, exige pensar sobre os aportes que balizam a sua interpretação. É nessa perspectiva que consideramos fundamental essa espécie de revisita ao sentido dos princípios, conceitos e categorias. É assim que os tematizamos, interessadas em abordá-los como componentes da sustentação epistemológica e de compromisso metodológico no ensino. Por isso, a importância de pesquisá-los, para pensar sobre essas escolhas. Acessar esses alçapões envolve visitar esses lugares nos quais são guardados (ou escondidos) acordos de compreensões, que permitem entender o que peculiariza e sustenta nossa análise geográfica.

É importante tematizar essas dimensões teóricas por haver muita proximidade entre elas e também em razão da carência de clareza que se tem na escola e na Graduação em relação a essa sustentação da análise espacial. Princípios, conceitos e categorias são oferecimentos 
teóricos e discussões que correm o risco de serem trivialmente entendidos e utilizados, como, por exemplo, princípio compreendido como dado, conceito como encerrado e categoria como agrupamento de propriedades comuns. Além disso, também, podem ser superficialmente empregados, como no alerta de Bernardes (2011), em relação à categoria “comumente utilizada para designar diferentes espécies do mesmo gênero e/ou distinguir certos fenômenos que apresentam uma mesma característica geral” (p. 166). São os princípios, conceitos e categorias que no contexto científico-acadêmico, compõem o arcabouço teórico que sustenta as reflexões. São discussões importantes, pois envolvem "instrumentos intelectuais imprescindíveis a qualquer teoria” (idem. p. 165). O desafio é buscar as bases do pensamento geográfico, seja na história que o constitui, seja nos limites que se apresentam na atualidade diante da complexidade do mundo da vida e mesmo do pensamento.

Propostos enquanto processos enlaçados, discutimos destacadamente cada uma dessas dimensões, suas proximidades e singularidades, que compõem o corpus teórico da Geografia. E, a par disso, ensaiamos desnudar o que seja o pensamento geográfico, como ele se constitui como se configura, e como ele pode ser o caminho para uma educação que considere (na escola) não apenas um conjunto de informações, mas que encaminhe a desenvolver a abstração e fazer a teorização. Esta é uma vinculação que começa pela compreensão de que as palavras envolvem conceitos, e avança com o entendimento de que os conceitos podem ser tratados em relações com categorias de análise que, de algum modo, podem ser relacionados com princípios científicos elaborados.

\section{Princípios geográficos}

Os princípios são enunciados que podem ser entendidos como fundamentos nunca últimos nem primeiros, mas que se vinculam com os campos do conhecimento e são por eles assumidos de modo específico em acordo com a "lógica" desse campo. Isso porque apresentam elementos estruturantes que permitem a análise pautando-se em leis e acordos com os quais se podem compreender aspectos específicos que os constituem. Mesmo entendidos como estruturas que contêm uma lógica, cabe lembrar que são sempre interpretações acordadas provisoriamente por determinada comunidade científica, porque os fundamentos e lógicas são elaborações humanas. A ideia de movimento é fundamental e envolve as capacidades de entendimento e compreensão das questões considerando os aspectos cognitivos, de cunho 
cientifico, os sentimentos, as emoções, a razão, quer dizer tem a ver com os humanos que somos.

García Ruiz, Jiménez e Rodríguez (2009) discutem e elaboram uma proposição de argumentação, interessada em oferecer elementos de sustentação para o ensino de Geografia e de História e, nesse sentido, resumem assim a importância do princípio:

[...] Constitui uma opção epistemologicamente fundada e útil na aprendizagem dessas duas disciplinas, uma vez que é inerente à natureza científica pela construção e especificidade do seu conhecimento, que ajuda a entender o todo das relações humanas em sua universalidade, é metaexplicativo e ajuda a compreender a complexidade de fatos e informações subsistentes, adapta-se à individualidade dos alunos, desenvolve habilidades e competências, destrezas e educa em valores, atitudes e normas (GARCÍA RUIZ; JIMÉNEZ; RODRÍGUEZ, 2009, p. 31).

Os pesquisadores espanhóis argumentam que os princípios têm um sentido não apenas científico, mas também didático, porque são sustentados epistemologicamente e inerentes aos processos de mediação no ensinar e no aprender na escola. Para eles, os princípios “ajudam, portanto, a estruturar com rigor científico os temas, a alinhavar os programas, ao mesmo tempo em que oferecem maior clareza e compreensão aos alunos(as)" (GARCÍA RUIZ; JIMÉNEZ; RODRÍGUEZ, 2009, p. 38). Eles entendem que os princípios se constituem não como organizadores dos programas, mas como formadores das unidades de cada tema. Constituemse como uma forma de acercar-se dos temas identificando sua natureza e dimensão, aprofundando-se nela, compreendendo seu valor formativo e sua função na ciência e na sociedade. Afirmam ainda ajudar não apenas a relacionar objetos e fatos, mas a entender o conjunto das relações humanas e do universo para além da área e da disciplina.

São linhas e eixos de continuidade, formas de conexão de conteúdos, vínculos interdisciplinares, mecanismos horizontais e transversais, ferramentas de análise, habilidades intelectuais, instrumentos didáticos, etc. Em resumo são meio e mensagem, método e objetivo, plano para o estudo e a compreensão da Geografia e a História da humanidade (GARCÍA RUIZ; JIMÉNEZ; RODRÍGUEZ, 2009, p. 38).

Argumentam os autores, que os princípios são parte da natureza intrínseca dos fenômenos, fatos e acontecimentos. Segundo eles, referem-se a fatos naturais e físicos, bem como sociais e espirituais. Nesse sentido, oferecem e explicitam detalhada e sistematicamente os princípios que entendem se relacionar com a Geografia e a História e são, por eles, assim apresentados: 
Espacialidade: onde isso acontece ou aconteceu? Temporalidade: quando isso acontece ou aconteceu? Conflito-consenso (modalidade): como isso acontece ou aconteceu? Atividade-mudança e continuidade: como tem evoluído ou evolui? Intencionalidade: o que eles pensavam, o que eles queriam? Interdependência: O que ou quem está envolvido ou que foram envolvidos? Causalidade, por que isso acontece ou aconteceu? Identidade: o que são ou foram características essenciais? (GARCÍA RUIZ; JIMÉNEZ; RODRÍGUEZ, 2009, p. 49).

Os pesquisadores propõem que os princípios formam metacategorias que diferem dos conceitos por sua versatilidade, por mergulharem e permanecerem acima de todos os conceitos e fatos. Entendem que "o conceito tem um significado específico, um campo mais ou menos definido e é contínuo em sua missão, enquanto o princípio não" (GARCIA RUÍZ; JIMÉNEZ, 2006, p. 65-67).

Princípios (do latim princípius) podem ser entendidos como "o primeiro instante do ser de uma coisa, ponto que se considera primeiro em sua extensão ou coisa, base, origem, razão fundamental sobre a qual se procede discorrendo em qualquer matéria; qualquer das primeiras proposições ou verdades fundamentais por onde se começa a estudar as ciências e as artes" (GARCIA RUÍZ; JIMÉNEZ, 2006, p. 63). Ainda que queiramos assumir essa afirmação, é necessário considerar que as noções de anterioridade, fonte, motivo ou sentença são apenas uma escolha e um percurso analítico, uma vez que "o porto" no qual ancoram as afirmações é construído dialógica e contextualmente, portanto não há apenas um, mas é um dentre outros "portos" e, se é "seguro", o é titubiante e provisoriamente.

As considerações sobre os princípios servem à reflexão sobre a perspectiva científica e didática, porque oferecem uma ideia da articulação e da identidade à Geografia em torno de seu objeto. Não podem nem devem, porém, ser entendidos como naturalizados. A natureza à que se referem os pesquisadores é uma construção no âmbito das compreensões humanas, ou seja, não é dada, mas é uma interpretação dos sujeitos. Princípio é um oferecimento de dispositivo, dentre outros, possível para pensar o objeto da Geografia como diálogo acadêmico-científico de seus pesquisadores e também como integrante de uma generalidade que envolve outras áreas. Os princípios compõem uma conjugação teórica da Geografia e podem ser relacionados com os conceitos e as categorias geográficas.

\section{Conceitos geográficos}

$\mathrm{Na}$ Geografia, as ferramentas teóricas, na forma de conceitos e categorias e seu uso como ferramentas intelectuais para a análise espacial, apresentam uma dificuldade que pode estar relacionada com "o passado da Geografia como uma ciência essencialmente empiricista, 
que não valorizava o papel da teoria e do conceito na produção do conhecimento" (CRUZ, 2010, p. 1). Essa dificuldade é evidenciada na escola, porque os professores passam a utilizar uma terminologia sem terem, muitas vezes, a preocupação com sua contextualização, podendo ainda o uso tornar-se punitivo (CASTROGIOVANNI, 2011), pois é tratado como tarefa necessária, mas pouco compreendida; uma forma de conteúdos tratados como fins, que se caracterizam pela repetição de temáticas da atualidade como fim e não como meio. Também nesse sentido, considerar o cotidiano como categoria da Geografia auxilia nesse processo de reflexão teórico-conceitual que avança na informação atual e pontual, que pode servir como dispositivo para pensar jogando com os limites, porque contém variantes espontâneas e criativas (WERTSCH, 1993), tese central da proposição neste artigo.

O enfrentamento dessa dificuldade de constituição do campo teórico na Geografia (que não lhe é exclusiva) permitiu a criação de variadas teorias, conceitos e categorias. É passível o entendimento de que há algumas categorias importantes à análise espacial como território, paisagem, lugar, região e conceitos como o de escala, bem como rede e orientação, como afirmado por Cruz (2010).

\begin{abstract}
A Geografia como qualquer campo disciplinar construiu ao longo de seu percurso uma grande variedade de teorias, conceitos e categorias analíticas, mas há um razoável consenso de que existem algumas categorias estruturantes desse campo científico: $o$ espaço, a paisagem, o território, o lugar e, mais recentemente, poderíamos incluir também o conceito de rede. Esses são considerados pela comunidade como aqueles que conferem uma relativa identidade à Geografia como ciência (p. 2, destaques do autor).
\end{abstract}

Na sequência dessa afirmação, ao debater o uso e a operacionalização dos conceitos na pesquisa em Geografia, Cruz (2010) indaga sobre quais são e como podem ser utilizados esses conceitos nas pesquisas. Justifica isso porque a categoria contém uma generalidade, ou seja, é um conceito, embora se distinga por implicar também perspectiva de análise, uma confluência de aspectos que são considerados para se realizar a avaliação. É importante refletir sobre o que Cruz (2010) refere, ou seja, atentar para a afirmação do conceito numa perspectiva estritamente realista - empírico-positivista -, que pensa o conceito como simples forma de divisão e taxionomia do real, podendo ser considerado estritamente idealista e arbitrário. O conceito não pode ser tratado numa perspectiva excludente, mas dialógica, porque envolve a materialidade teórica que tem uma concretude. Mesmo numa compreensão dialógica entre o empírico e o teórico, porém, é preciso levar em conta o que sugere Cruz (2010) ao citar Haesbaert, afirmando que a "construção do conceito implica numa operação onde o vetor é sempre do racional para o real" (p. 4). Nesse sentido, o conceito é uma reapresentação (diferenciada do real), é um 
instrumento de mediação (como meio de ação) e também um acionador, um fundador de realidades (CRUZ, 2010).

O conceito é relacionado com uma proposição mais ou menos ordenada, porque abarca especificidades que o caracterizam e peculiarizam. Um conceito, no entanto, embora seja uma generalidade, não tem fronteiras fechadas ou rígidas; por isso pode ser entendido como dispositivo aberto para pensar (WERTSCH, 1993) e que nos põe a refletir, como sugere Gallo (2008).

Os conceitos [...] são mobilizadores e motores do pensamento, estão para fazer pensar, não para paralisar, imobilizar o pensamento. Cada conceito remete a outro conceito, a outro problema. Cada conceito conecta-se com vários outros e pede novas conexões. Assim, num movimento infinito do pensamento, o que temos é sempre novos conceitos sendo criados, por conexão, por deslizamento, por deslocamento... e a invenção de novos problemas, como num moto contínuo (p. 66, destaque do autor).

Nesse sentido proposto por Gallo (2008), a elaboração de conceitos é um modo de mudar o mundo, criação essa, entendida sempre como proposição arguida provisória, nunca como verdade peremptória. Maffesoli (2008) infere outra possibilidade: a substituição da expressão conceito por noção, que considera mais aberta e prospectiva do que a palavra conceito.

[...] Há uma inflação de conceitos. Em todos os domínios, parece ser um termo-chave, apesar de não dizer mais nada. Por quê? Porque conceito significa tudo aquilo que é fechado, e, portanto, é próprio dele isolar o objeto como um produto finito e acabado. A imagem que faço de conceito é a do cocô da criança, orgulhosa de mostrá-lo à mamãe. É o que fazem muitos intelectuais a respeito de suas criações. Quero, no entanto, dar uma dimensão mais aberta, e, por isso, [...], procuro usar o termo noção, a fim de buscar uma instrumentação congruente com o momento vital. É preciso encontrar noções menos verdadeiras possíveis. O conceito busca a verdade. A noção busca a semelhança (MAFFESOLI, 2008, p. 3).

Uma proposição que, segundo o autor pode ser aproximada da "humildade da noção". $\mathrm{Na}$ análise oferecida pelo pesquisador, o cotidiano é conceito que pode ser proposto como categoria, pois pode ser compreendido como elo prospectivo ao diálogo escolar. O conceito permite "indicar a determinação de um aspecto singular do real" (BERNARDES, 2011, p. 167). $\mathrm{O}$ autor o sugere como formas fundamentais de pensamento depreendidas pela determinação de aspectos eleitos para a análise, e que possui a "universalidade como um dos seus principais aspectos" (BERNARDES, 2011). Se o conceito é uma generalização, a categoria é um modo de conhecer e de pensar. Nesse processo os conceitos estão intrinsecamente envolvidos, não como meras palavras, mas como signos que representam significados provisoriamente estáveis. 
"A academia entende por conceito (do latim conceptus) o pensamento expressado em palavras" (GARCÍA RUIZ; JIMÉNEZ, 2006, p. 63). Pode ser entendido como enunciado em palavras, que abriga "ideia ou ideias comuns acerca das coisas comuns, os esquemas mentais que representam a realidade, aspecto, qualidade, título, etc.” (GARCÍA RUIZ; JIMÉNEZ, 2006). É uma representação em palavras que diz algo maior do que e o que pode ser por elas abrigado. É, no caso, uma generalização aberta, porque sempre em processo de construção.

O conceito remete a uma generalização rica em abstração. Não é apenas um simples conjunto de conexões associativas, mas envolve um ato de pensamento, de generalização (VIGOTSKI, 1979, 1991, 1993-1997, 2001, 2012). Abrange uma gama de características peculiares que, uma vez compostas, podem ser reunidas, confluindo para uma ideia abstrata. De igual forma, englobando aspectos, constitui, pela linguagem, uma generalidade. Uma amálgama de atributos permite compreender a relação com determinado significado, ainda que cada sujeito o entenda de modo específico. Mesmo não sendo iguais em todas suas configurações, esses significantes têm propriedades que lhe atribuem um significado comum, que pode ser reunido e compreendido pelo conceito que os representa. Ainda assim, por conter elementos generalizantes, que, de algum modo, se vinculam socialmente, permite que seja possível entender tratar-se de determinado conceito que é uma generalização que contém sentido materializado em palavra. Tem uma concretude que conflui em materialidade teórica ou é materialidade teórica que resultou de uma concretude. Uma generalização (que tem uma "concretude" abstrato-concreta) materializada teoricamente em palavra.

Os conceitos de clima ou rede, por exemplo, confluem em uma generalização que permite depreender vínculos como significados. Um conceito constitui-se como abertura à reflexão que (não apenas), no ensino escolar, acarreta um elemento mediador às reflexões. A análise do conceito de clima e rede, então, no caso da Geografia, pode ser desencadeada na perspectiva das categorias: lugar (que tem a especificidade do acabar juntos), priorizando relações entre o(s) “onde(s)" diferentemente articulado(s) e atravessado(s) (relacional); de território (que permite a reflexão sob a ótica da apropriação, do poder sobre determinada área), privilegiando a perspectiva das relações de "poder (propriedade e apropriação)"; de paisagem (que foca o olhar sobre o arranjo - não apenas visível - resultante das interações dos elementos e das ações em dado local e tempo), atribuindo relevo aos elementos "em um local, em um tempo"; e região, ao privilegiar relações "entre lugares" a partir de alguns critérios escolhidos.

\section{Categorias geográficas}


São as categorias que resultam na Geografia (MOREIRA, 2008) porque abrem a leitura espacial que constitui a disciplina. Servem para pensar o espaço geográfico que é a categoria central à análise geográfica. Ao discutir o que considera como categorias tradicionais, Milton Santos (2008a) destaca a região, o lugar, a paisagem e o território na perspectiva urbanoindustrial e as novas relações com o campo como leituras mais atuais que consideram a produção e a circulação. Atenta que a "teorização depende de um esforço de generalização e de um esforço de individuação" (p. 65). Essa perspectiva se aproxima da possibilidade de peculiarização teórica da categoria em relação ao conceito, porque abriga epistemologia e metodologia; uma categorização científico-didática, pois “a generalização nos dá a listagem das possibilidades; a individuação nos indica como, em cada lugar, algumas dessas possibilidades se combinam" (SANTOS, 2008a) e como podem ser compreendidas e interpretadas. Todas essas categorias instituem-se como redes políticas, econômicas e socioculturais, nas quais elos e limites servem como horizontes no percurso à análise espacial. Milton Santos (2004, 2008a, 2008b, 2008c) as discute como categorias analíticas, enquanto argumenta o espaço como categoria permanente.

[...] Seria uma categoria universal preenchida por relações permanentes entre elementos lógicos encontrados através da pesquisa do que é imanente, isto é do que atravessa o tempo e não daquilo que pertence a um tempo dado e a um dado lugar, quer dizer, [...] o transitório, fruto de uma combinação topograficamente delimitada, específica de cada lugar (SANTOS, 2008b, p. 151).

As categorias que Milton Santos considera como analíticas são também respeitadas nas análises interessadas em pensar o Ensino de Geografia. A especificação da categoria pode ser, então, estabelecida mais pela relação do que pela separação entre conceito e categoria, quando o conceito é analisado como forma à análise (espacial), no sentido de que, desde logo, desde a disposição para pensar, a categoria tem como pressuposta a convocação do sujeito à participação no processo reflexivo, que envolve conceitos abrangentes a partir de uma perspectiva escolhida. Essa perspectiva de análise abrange a clareza do âmbito teórico do objeto e dos conceitos envolvidos. Assim, tendo-se o espaço como categoria central e objeto da Geografia, Santos (2004) apresenta uma relação de categorias internas analíticas que devem servir à analise espacial.

Entre elas, estão a paisagem, a configuração territorial, a divisão territorial do trabalho, o espaço produzido ou produtivo e as formas-conteúdo. Da mesma maneira e com o mesmo ponto de partida levanta-se a questão dos recortes espaciais, 
propondo debates de problemas como o da região e o do lugar, o das redes e das escalas (SANTOS, 2004, p. 21, destaques nossos).

Nesse sentido, recortes não podem ser tratados como fragmentos, mas critérios para a análise. Sugere Milton Santos que os elementos analíticos podem ser entendidos como categorias de análise que, "formando sistema, devem esposar o conteúdo existencial, isto é, devem refletir a própria ontologia do espaço, a partir de estruturas internas a ele” (2004, p. 23). Haesbaert (2011) interroga o sentido da categoria no senso comum simplesmente como um “conjunto de espécies do mesmo gênero. [...] reunidas sob um determinado nível de generalização" (p. 109). Aristóteles propõe categorias como modos fundamentais de ser, e Kant como modos fundamentais de conhecer (MÜLLER; HALDER, 1976, p. 66-67), porque entende que as categorias "não descrevem a realidade, mas tornam possível explicá-la" (MORA, 1998, p. 82). No contexto dessas proposições, Haesbaert (2011) sugere entender categoria como "uma espécie de "conceito mais amplo"” (p. 110, destaque do autor), e isso explica o espaço como categoria central, que serve para diferentes relações na perspectiva de lugar, território, paisagem e região entre outros.

“A construção de um sistema interior a cada ciência particular só pode ser feita se as categorias de análise são ajustadas à categoria do real. É o chegar-se a uma síntese, e ninguém ignora que sem síntese não há ciência” (SANTOS, 2008b, p. 149). Isso ajuda a pensar nas categorias, distinguindo-as por serem entendidas como perspectivas de análise da abrangência de aspectos relacionados com o objeto em determinado campo de conhecimento, como já afirmamos. Dizendo de outro modo, são instâncias como lentes focais a partir das quais é possível vislumbrar uma análise. Isso configura uma escolha, no contexto da qual o pesquisador ou o intérprete abre a reflexão sustentando-se em alguns aspectos teóricos que se prestam para a análise do objeto central; uma análise que traz ao debate alguns elementos que, de outra forma ou inseridos em outra categoria - como cotidiano, por exemplo, imerso na categoria lugar -, fica obscurecido. Ao especificar o enfoque de cotidiano, é evitado o risco de esmaecer a categoria já reconhecida em sua especificidade (o lugar) e enfraquecer noção diferente (embora relacionada) que se pretende suscitar (o cotidiano). Categorias analíticas "reproduzem, no âmbito da ideia a totalidade dos processos, tal como eles se produzem na realidade" (SANTOS, 2008b, p. 149, destaque do autor).

Tomamos a reflexão de Haesbaert (2011) para salientar que cada categoria também se configura em um conceito e que estes servem para a análise sob a óptica da categoria e esta para ler determinados conceitos. A categoria é peculiar por se apresentar como "instrumento 
analítico e recurso metodológico" (HAESBAERT, 2011, p. 115). Como categoria, que dá ênfase a uma "determinada perspectiva ou forma de olhar" (id. p. 116), serve como parâmetro para a leitura de outros conceitos além de deles se utilizar para realizar essa análise focada.

Por abrir à análise que joga o foco sobre "algumas propriedades e/ou dimensões" (HAESBAERT, 2011), a categoria tem uma função de servir também como movimento metodológico em cada campo. Isso porque permite extrair análises em diferentes escalas e patamares de interpretação dos conceitos presentes em cada recorte que se pretenda debater. A escolha de uma categoria para a realização da análise exige privilegiar alguns e minimizar outros elementos e aspectos de um local. Isso permite focar, com maior precisão, certos predicativos que desejamos ressaltar. Ou seja, grifamos e acentuamos alguns e esmaecemos outros aspectos de uma parcela do espaço que pretendemos considerar no estudo.

Por envolver atributos que dizem respeito a um sujeito, a categoria se refere aos diferentes pontos de vista a partir dos quais os sujeitos interpretam e, assim, constroem os caminhos por meio dos quais é possível conhecer. São diversas maneiras de interpretação e expressão dos sujeitos. A categoria geográfica incide, assim, no realce de alguns aspectos do espaço geográfico. Essa é uma importante perspectiva da análise, em virtude de que não é possível considerar todos os aspectos da espacialidade. No espaço local, regional e global, visto sob a ótica da espacialidade física, social, econômica, política e cultural, ocorre multiplicidade de movimentos, o que exige uma análise que inclua alguns e exclua outros elementos. É uma análise na qual há uma espécie de corrimão selecionado e que, anunciado, deixa evidentes os critérios que serão levados em conta na análise espacial, numa perspectiva espacializada de olhar determinada área (ANDREIS, 2012, p 134-139). Isso diz respeito às escolhas, pois todo o currículo e tudo o que é trabalhado na escola passa por seleção, eleição e definição de pauta. A identificação do objeto será de pouca significação se não formos capazes de definir-lhe as categorias fundamentais.

[...] Sem nenhuma dúvida as categorias sob um ângulo puramente nominal, mudam de significação com a história, mas elas também constituem uma base permanente, e, por isso mesmo, um guia permanente para a teorização. [...] São os fatores referentes à gênese, ao funcionamento e à evolução do espaço que nos interessam em primeiro lugar (SANTOS, 2008b, p. 147).

Para Milton Santos (2004), as categorias são o movimento da realidade, porque são elas que abrem à análise dos conceitos, segundo determinadas perspectivas estabelecidas para esta investigação. As categorias são modos de "capturar" (MAIA; ALVES, 2009) elementos para a leitura e análise espacial; uma proposição importante, pois, "ainda que nossas(s) categoria(s) 
e/ou nossos conceito(s) não consiga(m) encontrar exatamente uma resposta, ou uma resposta precisa, o simples fato de elucidar(em) ou de tornar(em) mais claras nossas próprias questões, já pode ser considerado um grande avanço” (HAESBAERT, 2011, p. 118).

Revisitando essas questões em autores que podem nos dar a sustentação de pensar com um cunho científico o fazer da sala de aula, abrimos caminhos para olhares novos no sentido de superar o reprodutivismo no ensino da geografia (que é o que nos interessa pensar) e encontrar alternativas. Essas se sustentam ou podem ser sustentadas a partir da necessidade de compreender que a escola é o lugar da aprendizagem onde se realiza a abstração e a generalização, que necessariamente supera o senso comum. Não é fácil quando se tem a realidade que conhecemos, seja ela caracterizada pela precariedade do trabalho do professor pela sua formação e pelas condições de trabalho; pelo uso do livro didático que fornece o que e como deve ser abordado em cada ano/serie da vida escolar; pela busca insistente de metodologias e estratégias para que o aluno aprenda; pela formação inicial dos professores que se apresenta com inúmeras carências; pela formação continuada que é, na maior parte das vezes, um exercício fragmentado de oferecer palestras e conferencias e/ou oficinas como novidades. Isso tudo precariza o trabalho do professor, e as aulas de geografia ainda continuam,reproduzindo sequências de conteúdos e informações do livro didático.

Como exercício de pensamento e busca de construção de alternativas que não sejam meras receitas pra dar certo o ensino, através do oficio de pesquisar ensino de geografia e de atuar em sala de aula na formação docente desenvolvemos uma argumentação que tem forte base de sustentação teórica e que não esquece a dimensão do empírico - pois que a conhecemos. Essa análise que está aqui exige, por nossa convicção, avançar e pensar também as possibilidades de fazer diferente. Não apenas para ser diferente mas para pensar também a pratica e as possibilidades de avançar na constituição de um sentido para o ensino de geografia, de modo a que seja mais do que mera disciplina a compor o currículo escolar. E ai floresce o que denominamos de imaginação criadora.

\section{MEDIAÇÃO DIALÓGICA}

Tratadas como interpretações vinculadas entre si, as sistematizações devem ser assumidas como possibilidades, nunca como fragmentos e limitações à imaginação criadora. É com esse sentido que propomos um mapa conceitual, que pode contribuir para pensar sobre a relevância da sustentação teórica, enquanto aporte à imaginação criadora.

Figura 1: Dialética-dialógica da aula de Geografia 


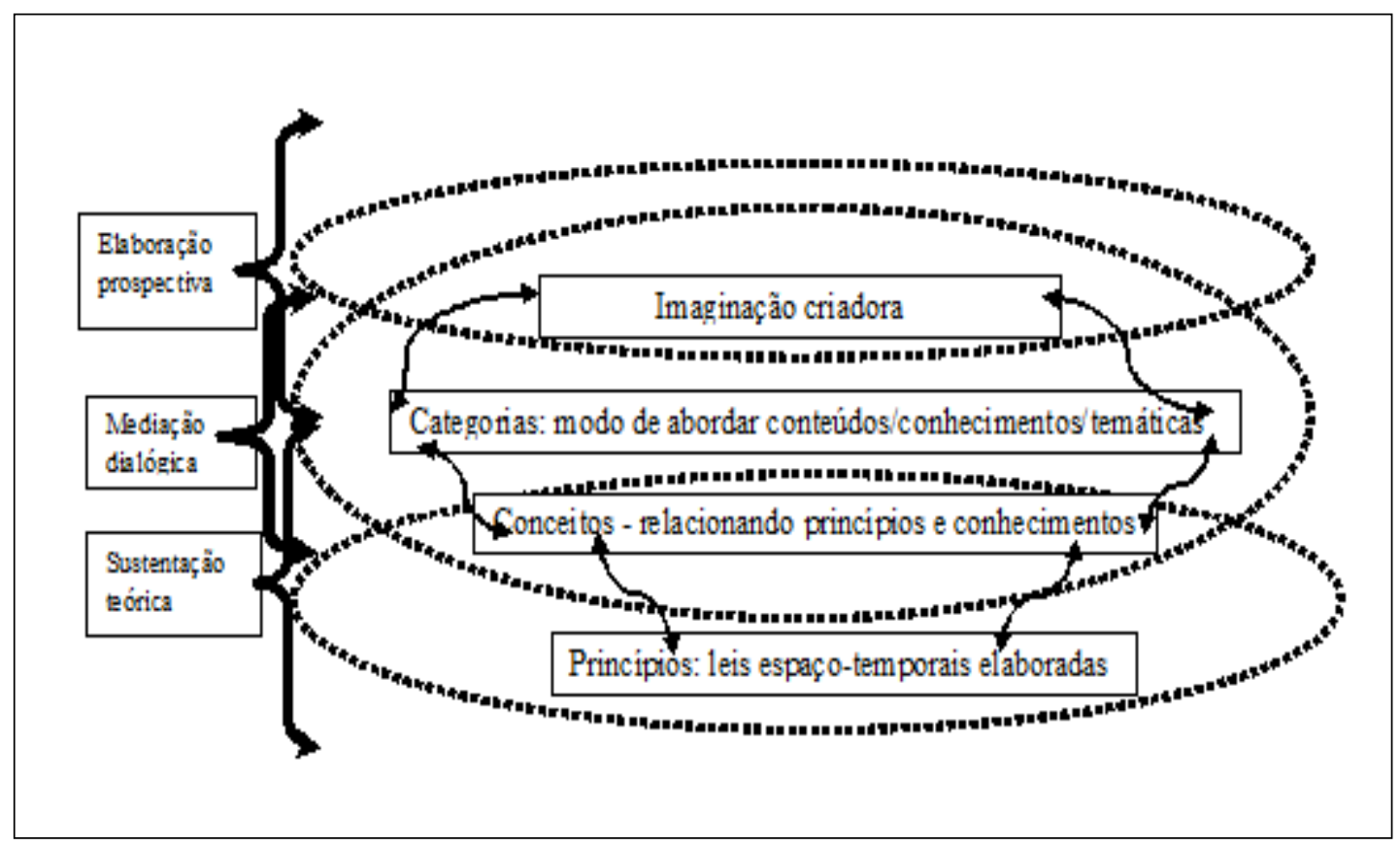

Fonte: Elaboração das autoras (2017)

Esse modo de apresentar a relação, que sustenta a análise espacial pelo viés geográfico na aula, deve ser entendido na perspectiva da dialética-dialógica. É apresentado na forma de espiral cíclica, pois compreende relações entre os sentidos dos sujeitos e os significados, inerentes ao processo educativo da escola, ou seja, como "diálogo propositado". Este entendimento de aula dialoga com a discussão de Bulavka e Busgalin (2005), pois envolve assumir que "[...] o sujeito não se relaciona com o outro de modo funcional como um computador e um vendedor ou como um superior e um subordinado". A relação "entre os sujeitos no diálogo é um relacionamento entre sujeitos integrais qualitativamente, cuja interação faz nascer uma nova (e terceira) qualidade, o diálogo" e "a natureza dessa interação qualitativa pode ser entendida apenas no contexto da lógica dialética”. (p. 6-7, destaque dos autores). Portanto, essa apresentação (na forma de figura) não pode ser tomada como relação linear e vertical, uma vez que é possível dinamizar as relações entre os princípios, conceitos, categorias e a imaginação criadora. Porém, apresentando uma perspectiva escolar, tratamos de acentuar o “diálogo propositado", por isso essa abordagem é destacada.

A figura apresenta três dimensões para expressar que: (a) os princípios são alicerces criados e que configuram os conceitos, (b) servindo como referência para as relações com os conteúdos, cuja abordagem pode ser realizada por meio das categorias, (c) servindo às relações livres, abertas e novas. Esses enlaces dialogam com a perspectiva do espaço geográfico, pensando o mundo como dimensão do social (espaço), que envolve a dimensão da mudança (tempo). Resulta, portanto, da relação dinâmica e dialética, oportunizada na aula de geografia, 
pautada em princípios espaço-temporais de natureza teórica, que são elaborados (porão), para servir de referência às análises das temáticas colocadas em questão na aula (casa). Essa relação provocada põe em diálogo as singularidades dos sujeitos e a generalidade dos princípios, conceitos e categorias, que abrem à imaginação criadora, enquanto elaborações criativas e criadoras de mundo (sótão). Note-se, que na figura os conceitos estão situados entre os princípios e os conteúdos, pois os entendemos como noções articuladas com os princípios e que, na aula, compreendem o eixo singular de cada disciplina. Assim os conceitos assoalham os conteúdos lidos por meios de categorias, que habitam a casa. Conceitos, categorias e conteúdos estão, então, como processos mais visibilizáveis no corpo das aulas, como dispositivos implicados na mediação dialógica. Os princípios por compreenderem a sustentação teórica e a imaginação criadora, por envolver elaborações prospectivas, envolvem o que denominamos de aquém e além da aula, portanto, menos visualizáveis.

É possível dinamizar a posição desses componentes que sustentam a aula? Sim se estivermos interessados em provocar reflexões acerca do processo. Mas a resposta é não se entendermos na perspectiva de que o conhecimento científico - lembrando o compromisso de reconhecer os conhecimentos originais, para evitar o "desperdício de experiências", como propõe Boaventura Santos (2007) - é elo prospectivo, porque, diferentemente dos conhecimentos cotidiano - que são mais espontâneos - provocam sistematicamente à prospecção. Também nesse sentido, o imaginar admite, mas não pode ser confundida com o fantasiar. Assumimos essa proposição, porque entendemos que imaginar dialoga mais de perto com o pensar criativo e a criação livre, enquanto que o fantasiar dialoga mais de perto com a livre criação. E, a aula é o espaço-tempo para o "confroencontro propositado" (ANDREIS, 2014) de ideias, que se realiza entre sujeitos singulares, de natureza social, na qual esse complexo processo - interessado em pensar o mundo - é colocado em movimento.

Princípios, conceitos e categorias espaciais se constituem em elos teóricos, que peculiarizam a análise geográfica na aula, pois é preciso se firmar em uma base, mesmo que essa base seja escolhida e provisória. Ela é a possibilidade de avançar prospectivamente na reflexão. O esforço dessa conceituação é entendido como um caminho e uma chave de abertura às reflexões acerca dos conteúdos nas aulas de Geografia. Esse entendimento não é na perspectiva da exclusão, que vizibiliza um e invizibiliza outro, mas da relação, uma vez que é assumido como diálogo e interessado em reconhecer o objeto próprio da Geografia.

Projeções cartográficas, clima, redes, relevo, orientação, política, sociedade e economia, entre outros, são exemplos de conceitos como generalizações compostas como atos (abertos, 
provisórios) de pensamento, como modos de compreensão arranjados, segundo determinados aspectos escolhidos, sustentados pela atribuição de certo enfoque. Estão envolvidos na análise espacial realizada sob a perspectiva da categoria geográfica. São conceitos que, de algum modo, se objetivam e têm na essência a relação com os objetos e as ações que se processam em interação em dada espacialidade. As categorias entre si estão entrecruzadas por conceitos comuns que servem ao esforço sobre o qual jogamos o foco e os critérios para a análise.

Esta reflexão permite afirmar, que os conteúdos escolares podem ser entendidos como dispositivos reflexivos e assumidos como geográficos, se analisados e compreendidos como enlaçados em princípios elaborados provisoriamente. A estes estão relacionados os conceitos, que são generalizações que permitem ler os assuntos destacando o viés especial. As categorias, por sua vez, são caminhos oferecidos como modos de pensar o espaço. Refletindo acerca dessas relações, para pensar sobre o que sustenta a análise espacial pelo viés geográfico no ensino, esta discussão se propõe a contribuir com a educação geográfica.

Podemos denominar de conhecimentos ou de conteúdos da aula os temas nela postos em discussão. O que precisamos ter claro é que não devem ser tratados como meras informações e/ou dados que expressam realidades estanques, e que podem servir à análise em diferentes áreas. Por isso, é importante considerar que há um “porão” (referentes geográficos: princípios), que sustenta a "casa" (conteúdos da aula de Geografia, entremeados por conceitos e categorias). São esses alicerces que permitem construir o "sótão" (prospecção, imaginação criadora). A reflexão sempre é pautada em elos de significados. Ainda, apontamos que a realidade é irretratável, pois é mais dinâmico-dialética do que as construções teóricas (ANDREIS, 2010). No entanto, o avanço compreensivo emancipatório (sótão) nas aulas (casa), tem relação de dependência com a clareza acerca dos alicerces ou pressupostos (porão) que as compõem.

\section{CONCLUSÃO: A POTÊNCIA AQUÉM E ALÉM DA AULA}

Retomando a metáfora do porão e do sótão da casa podemos delinear a construção do entendimento a respeito do que poderia ser o papel do professor se existirem as condições efetivas para que ele seja o protagonista da sua tarefa na vida profissional. Reiteramos neste sentido que não somos concordes com a existência de regramentos externos e distantes do professor. Qualquer proposição de encaminhamento da ação escolar de ensino e aprendizagem requer que o mediador (e este é o professor) tenha em mãos o controle do processo. E para tanto se retoma a questão da formação, que precisa ser consistente e coerente com os parâmetros da 
ciência que ensinamos e a dimensão pedagógica que precisa ser considerada no trato dos conteúdos.

Há necessidade sim, de existir um conjunto de ideias e proposições que sustentem o ensino para que este seja acessível a todos os estudantes de modo a que tenham as condições de se inserir na vida adulta como sujeitos que exerçam sua cidadania. E, além disso, para que exercitem neste momento de suas vidas como estudantes a condição de serem sujeitos que compreendem o seu papel nesse mundo, agora como estudantes - crianças e jovens. Só através da realização das ações que neste tempo e espaço lhes cabem eles podem constituir as bases para o seu futuro, pois entendemos que a escola tem que criar as condições de que cada um exerça a sua cidadania e compreenda o lugar- espaço e tempo em que está vivendo. O futuro não adianta tomarmos como base, pois dele só ele mesmo - o futuro - dirá.

As proposições que decorrem das políticas públicas para a educação precisam neste sentido ser acolhidas através da crítica que estimula o pensamento e do pensar que estimula a crítica. Vivemos num país que tem um território muito grande, que temos culturas muito diversas, e histórias dos lugares e das populações (os estudantes) que não podem ser submetidas a um regramento que vai cobrar deles determinados conteúdos, habilidades e competências definidas a todos como se houvesse homogeneidade. Algo deve existir que estabeleça os parâmetros de um cenário comum, mas como referência e não como detalhamento de ações a serem desenvolvidas. Se o nosso esforço é no sentido de fazer uma educação de qualidade para que a formação permita o acesso à justiça social precisamos encontrar caminhos, que não seja a definição de proposições únicas a todos os estudantes.

Mas neste sentido encaramos o outro desafio, que diz respeito a como considerar o aceso de todos os estudantes a um conhecimento que seja exequível e adequado ao exercício da cidadania. Não acreditamos em ensino menor ou melhor, pois todos devem ter acesso ao conhecimento. Existem sim realidades diversas e essas devem ser consideradas tendo um referente comum, mas que não deve ser um currículo ou proposição que enjaule a todos num mesmo interesse. $\mathrm{O}$ que vale é formar para a vida. Então temos a necessidade de considerar a realidade próxima, e o contexto em que vivemos e onde estão as escolas. Como fazer este processo andar de modo que tenhamos a referência que seja para todos os estudantes, sem distinção de condições a que estão submetidos.

O nosso entendimento é de que precisamos desenvolver o pensamento geográfico e para isso a clareza a compreensão dos princípios, categorias e conceitos se configuram como a base. Quer dizer essa dimensão remete ao porão, que sustenta toda a arquitetura da casa e que sem 
ela o professor ficará a mercê de aplicar propostas externas a seu próprio exercício docente. $\mathrm{E}$ nesse sentido se torna presa fácil de proposições que se dizem inovadoras e metodologias e aparatos tecnológicos para superar as dificuldades de sala de aula, o que não acontece, com êxito, ou muito raramente pode ser eficaz.

O nosso desafio está sendo elucidar os caminhos possíveis para que este pensamento geográfico possa ser desenvolvido, e isso exige desenvolver o próprio pensamento. Um pensar de resistência para avançar diante do que está posto tradicionalmente e que já faz parte do senso comum, mas sem descuidar da atenção com o que foi historicamente produzido pela humanidade. Este pensar de resistência pode delinear caminhos a partir do exercício da crítica, que exige conhecimento para não cair no discurso fácil. Se formos capazes de pensar - e acreditamos que somos sim - abrimos os caminhos para realizar aprendizagens significativas.

Se tivermos o porão bem fundamentado e bem esclarecido, e se for compreendido o seu papel, na continuidade da abordagem da nossa metáfora, teremos a capacidade de construir o sótão com a singularidade que nos exige o fazer pedagógico. A aula de geografia assentada no esclarecimento de para que servem estes conteúdos tem aqui a sua constituição de modo a ser realizada com significativos resultados para as aprendizagens. E isso sem cair na simplificação de abordagem de conteúdos para memorização ou no desenvolvimento de habilidades que remetem ao mundo rápido apenas, ao invés de se constituírem com sólidos argumentos para ser a base da vida.

Encaminhamos a argumentação afirmando a proposição acerca da fundamentalidade do diálogo propositado, pressuposto da ação educativa, assumindo que a espiral cíclica, dimensão espaço-temporal criada à aula de Geografia, a esta não se restringe. Isso, porque o espaço como dimensão do social e o tempo enquanto dimensão da mudança, estão implicados em todos os conceitos elaborados. Também, porque, enquanto processo epistemológico e percurso metodológico, os princípios, conceitos e categorias compreendem relações que sustentam todas as aulas das diferentes áreas do conhecimento e, inclusive, tanto da Educação Básica quanto da Graduação e, até mesmo, da Pós-Graduação.

\section{REFERÊNCIAS}

ANDREIS, Adriana Maria. La producción de significados y representaciones del espacio por la Geografía escolar: posibilidades y limitaciones en los mapas. Revista Geográfica de América Central. № 45, II Semestre 2010 p. 15-29. 

2012.

Ensino de Geografia: fronteiras e horizontes. Porto Alegre: ComPasso Lugar Cultura, Cotidiano: uma categoria geográfica para ensinar e aprender na escola. Tese (Doutorado), Universidade Regional do Noroeste do Estado do Rio Grande do Sul - UNIJUÍ, Ijuí/RS, 2014.

BACHELARD, Gaston. La poética del espacio. México: FCE, 1975.

BAKHTIN, Mikhail. Para uma filosofia do ato responsável. São Carlos: Pedro \& João editores, 2010.

BERNARDES, Antônio. Quanto às categorias e aos conceitos. Revista Formação Online, n. 18, v. 2, p. 165-171, jul./dez. 2011. Disponível em:

<http://revista.fct.unesp.br/index.php/formacao/article/viewFile/602/1225>. Acesso em: 15 maio 2013.

BULAVKA, Ludmila; BUZGALIN, Aleksander. Os próximos cem anos de Mikhail Bakhtin: a dialética do diálogo versus a metafísica do pós-modernismo. Revista Novos Rumos. Ano 20, n. 44, 2005 p.4-14. Disponível em:

<http://www2.marilia.unesp.br/revistas/index.php/novosrumos/article/view/2130>. Acesso em: 25 abr. 2013.

CALLAI, Helena Copetti (org). Educação geográfica: Reflexão e prática. Ijuí/RS: Editora da UNIJUI, 2011.

2013.

A formação do profissional da Geografia: o professor. Ijuí/RS: Editora da UNIJUI,

CRUZ, Valter do Carmo. Uma proposta metodológica para o uso/operacionalização dos conceitos na pesquisa em geografia. ENCONTRO NACIONAL DE GEÓGRAFOS - ENG, 16., Porto Alegre, 2010. Porto Alegre, 2010. Disponível em:

<www.agb.org.br/evento/download.php?idTrabalho>. Acesso em: 7 abr. 2013.

GERALDI, João Wanderley. A aula como acontecimento. São Carlos/SP: Pedro \& João Editores, 2010.

GALLO, Silvio. Filosofia e o exercício do pensamento conceitual na educação básica. In: Revista Educação e Filosofia, Uberlândia, v. 22, n. 44, p. 55-78, jul./dez. 2008. Disponível em: <http://www.seer.ufu.br/index.php/EducacaoFilosofia/issue/view/229>. Acesso em: 8 abr. 2013.

GARCÍA RUIZ, Antonio Luis; JIMÉNEZ, José Antonio; RODRÍGUEZ, Efrén. Bases teóricas do modelo de princípios científico-didáticos para o ensino de Geografia e História. Revista Paradigma, v. XXX, n. 1, jun. 2009, p. 31-61. Disponível em: <http://www.scielo.org.ve/pdf/pdg/v30n1/art03.pdf $>$. Acesso em: 18 out. 2012.

GARCÍA RUIZ, Antonio Luis; JIMÉNEZ, José Antonio. Los principios científico-didácticos $(P C D)$ : nuevo modelo para la enseñanza de la geografía y de la historia. Granada, España: Universidad de Granada, 2006. 
HAESBAERT, Rogério. Espaço como categoria e sua constelação de conceitos: uma abordagem didática. In: TONINI, I. et al. O ensino de Geografia e suas composições curriculares. Porto Alegre: UFRGS, 2011. p. 109-120.

MAIA, Adriano C; ALVES, Flamarion D. Categorias e epistemologia: reflexões teóricometodológicas na ciência geográfica. V Encontro de grupos de Pesquisa. Grupo de pesquisa em educação e território. Universidade Federal de Santa Maria (UFSM), Santa Maria, 25-27 nov. 2009. Disponível em: <http://w3.ufsm.br/gpet/engrup/vengrup/anais/4/Adriano\%20Maia_NEA\%20UNESP.pdf > Acesso em: 20 jan. 2013.

MAFFESOLI, Michel. A terra fértil do cotidiano. Revista Famecos, Porto Alegre, n. 36, p. 59, ago. 2008, quadrimestral. Disponível em:

<http://revistaseletronicas.pucrs.br/ojs/index.php/revistafamecos/article/viewFile/4409/3308>. Acesso em: 18 dez. 2012.

MARQUES, Mario Osorio. Escrever é preciso: o princípio da pesquisa. Petrópolis: Vozes, 2008.

MORA, José Ferrater. Dicionário de filosofia. São Paulo: Martin Fontes, 1998.

MOREIRA, Ruy. Para onde vai o pensamento geográfico? Para uma epistemologia crítica. São Paulo: Contexto, 2008.

MÜLLER, Max; HALDER, Alois. Breve diccionario de filosofía. Barcelona: Editorial Herder, 1976.

SANTOS, Boaventura de Sousa. Renovar a teoria crítica e reinventar a emancipação social. São Paulo: Boitempo, 2007.

SANTOS, Milton. A natureza do espaço: técnica e tempo. Razão e emoção. São Paulo: Edusp, 2004.

. Metamorfoses do espaço habitado. São Paulo: Edusp, 2008a.

. Por uma geografia nova. São Paulo: Edusp, 2008b.

Da totalidade ao lugar. São Paulo: EDUSP, 2008c.

VEIGA-NETO, Alfredo. É preciso ir aos porões. Revista Brasileira de Educação, v. 17, n. 50, maio/ago. 2012, p. 267-282. Disponível em:

<http://www.scielo.br/pdf/rbedu/v17n50/v17n50a02.pdf>. Acesso em: 2 abr. 2013.

VIGOTSKI, Lev Semenovich. El desarrollo de los procesos psicológicos superiores.

Barcelona: Gráfica Salvá, 1979.

A formação social da mente. São Paulo: Martins Fontes, 1991.

Obras Escojidas IV. Madrid: Visor, 1993-1997. 
A construção do pensamento e da linguagem. São Paulo: Martins Fontes, 2001.

La imaginación y la arte en la infancia. Madrid: Akal, 2012.

WERTSCH, James. Voces de la mente: un enfoque sociocultural para el estudio de la acción mediada. Madrid: Visor, 1993. 